\title{
SEVEN YEARS OF EXPERIENCE IN INTEGRATED CARE AND EDUCATION ON DIABETES IN CUBA: PROJECT "SWEET MY LIFE, NOT MY BODY".
}

\author{
Author: Dr. Rocío Rodríguez Sánchez ${ }^{1}$ \\ Co-author: Dr. Manuel Vera González²
}

\section{INTRODUCTION}

The re search is based on the experience of a project founded sevenyears ago promoting monthly meetings to orientate and educatehealthy life style in young people with diabetes \& their relatives.

\section{GROUP DESCRIPTION}

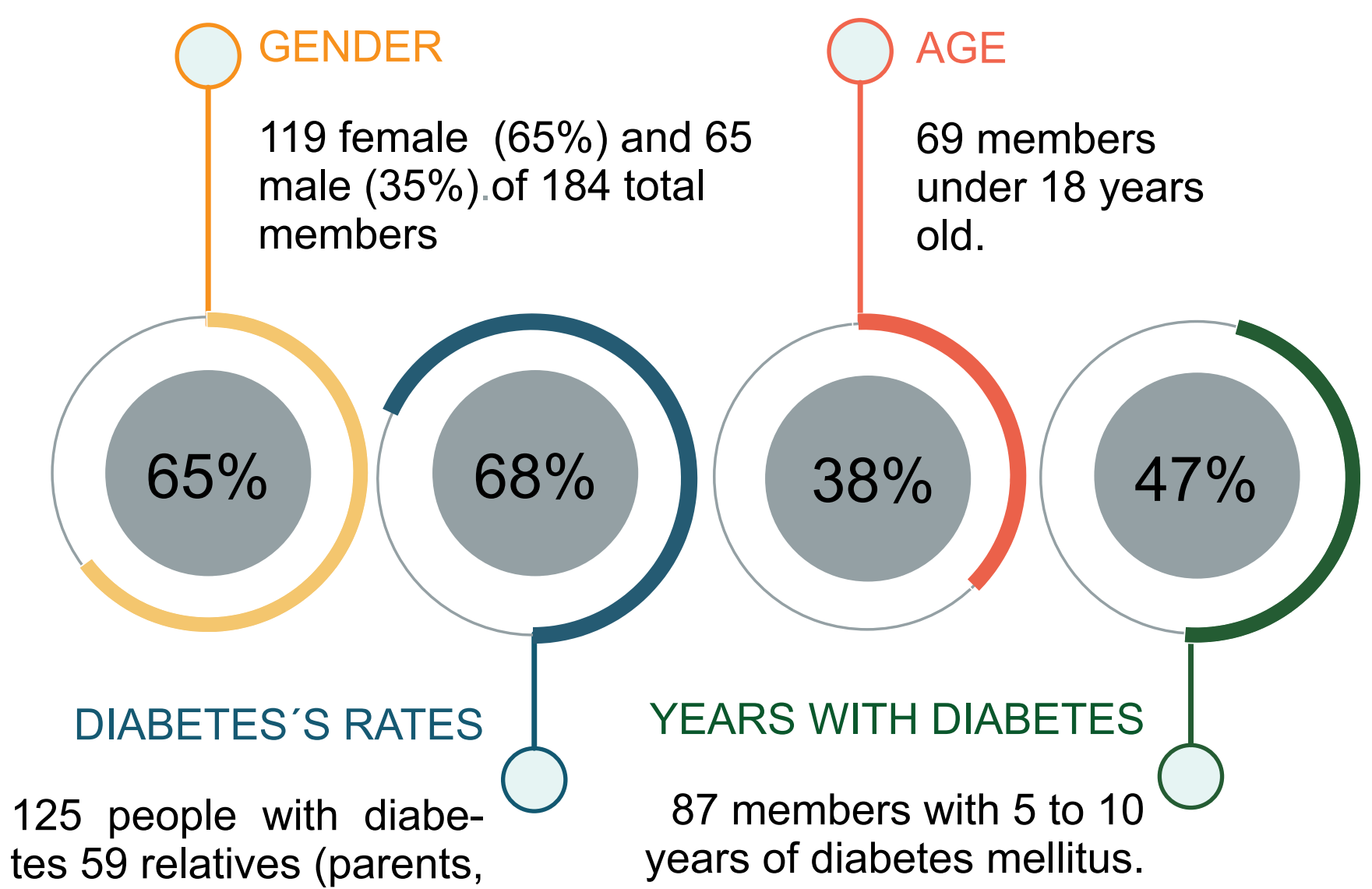
tes 59 relatives (parents, friends, couples).
Ing. Mabel Gómez Albertus ${ }^{3}$

Arq. Ricardo Machado Jardo ${ }^{4}$
Lic. Daili Carnero Gonzalez ${ }^{5}$

Arq. Oliesky Fabré Del Castillo ${ }^{6}$

\section{METHODOLOGY}

We studied qualitative andquantitativeperspectives,supportedby inquiries, interviews and focal questionnaries. Aims: To systematize the experience in education and integrated care on diabetes in Cuba. To develop a proposal for a diabetes educational program.

MAIN TOPICS*

01 LIVING WITH
DIABETES

02 DIABETES AND

03 DIABETES AND

04 DIABETES AND

04 DIABETESAND

05 MYTHS AND

06 SELF-ESTEEM,
STRESS.

07 DYSFUNCTIONAL

FAMILIES

08 SPECIAL

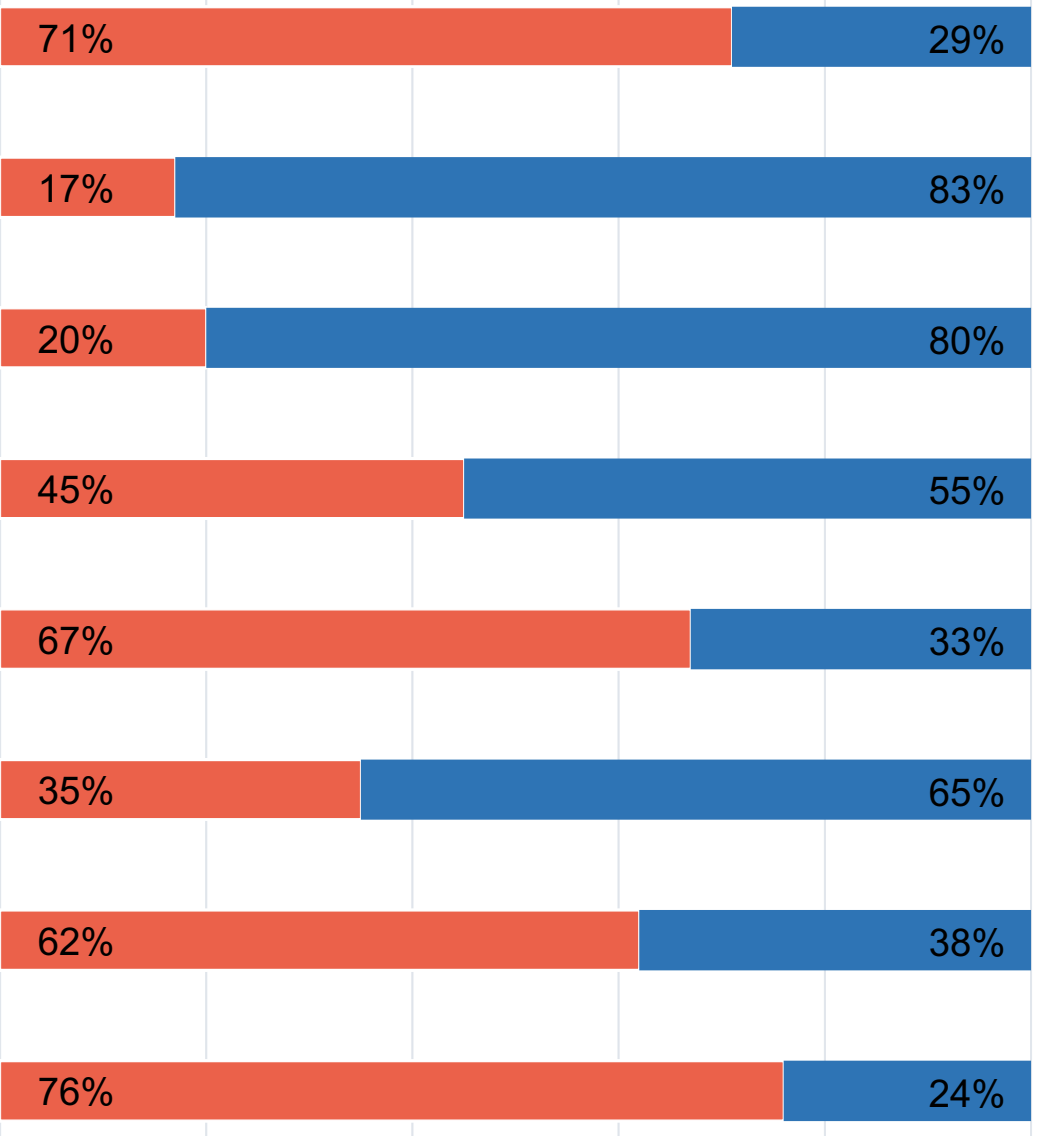

Relative's interest

Young member's interest

EDUCATIVE PROGRAM

WHY...?

EXPECTED RESULTS...?

General Evaluation criteria of the educative program (permanence, new incorporations, better metabolic control, knowledge measurement). Acceptance of being a person with diabetes and enjoy a healthy life style. Diminish or delay the onset of diabetes complications.

HOW...?

Identifying different methods that will be used in the planned activities.

Methodological values:

- participation-action

- collective production of knowledge

- start from the practice in the educative process.

- application of different educational techniques.

\section{WHAT TO DO...?}

Identify the topics and activities suitable to the main goals and the target audiences.

-workshops

-recreational activities

-community participation and inclusion

${ }^{*}$ Main Topics:

To identify the educative \& informative needs (levels of information, interaction, and dysfunctional family).

\section{WHAT FOR..?}

To select the main goals of the educative program.

Examples:

-strengthen the knowledge about diabetes.

- encourage the interaction between people with diabetes and their relatives.

- stimulate background related with healthy life style.

- emphasize the importance of diabetes as a social problem, not only a disease.

- acceptance of the condition of been a person with diabetes.

03

\section{TO WHOM...?}

To the target audiences:

- People living with Diabetes

- Relatives (parents, friends, colleagues, couples)

- Soport networks

- Scientific community

1.Living with diabetes: hypoglycemia, hyperglycemia, sweetening, foot care, oral health / 2.Diabetes and fashion : piercing and tattoos, physical exercise./ 3.Diabetes and sexuality : couple and diabetes, diabetes and pregnancy, sexual infections and contraceptives./ 4.Diabetes and nutrition: healthy food, sweet the spirit, not the bothe.\$5.Myths and prejudice: the family facing diabetes. / 6 . Self-esteem, 7.Dysfuntional families / 8.Special situations / 9.Among others. 